University of Nebraska - Lincoln

DigitalCommons@University of Nebraska - Lincoln

May 2007

\title{
Unique and Combined Contributions of Multiple Child Abuse Types and Abuse Severity to Adult Trauma Symptomatology
}

John C. Clemmons

University of Arkansas for Medical Sciences

Kate Walsh

University of Nebraska-Lincoln

David K. DiLillo

University of Nebraska-Lincoln, ddilillo@unl.edu

Terri L. Messman-Moore

Miami University

Follow this and additional works at: https://digitalcommons.unl.edu/psychfacpub

Part of the Psychiatry and Psychology Commons

Clemmons, John C.; Walsh, Kate; DiLillo, David K.; and Messman-Moore, Terri L., "Unique and Combined Contributions of Multiple Child Abuse Types and Abuse Severity to Adult Trauma Symptomatology" (2007). Faculty Publications, Department of Psychology. 266.

https://digitalcommons.unl.edu/psychfacpub/266

This Article is brought to you for free and open access by the Psychology, Department of at DigitalCommons@University of Nebraska - Lincoln. It has been accepted for inclusion in Faculty Publications, Department of Psychology by an authorized administrator of DigitalCommons@University of Nebraska - Lincoln. 


\title{
Unique and Combined Contributions of Multiple Child Abuse Types and Abuse Severity to Adult Trauma Symptomatology
}

\author{
John C. Clemmons \\ University of Arkansas for Medical Sciences \\ Kate Walsh \\ David DiLillo \\ University of Nebraska-Lincoln \\ Terri L. Messman-Moore \\ Miami University
}

\begin{abstract}
Studies have documented the co-occurrence and cumulative impact of multiple types of child maltreatment on later psychosocial difficulties. Other research suggests that child abuse characteristics indicative of severity may also increase risk of later adjustment problems. However, little effort has been made to examine the co-occurrence of both multiple types of maltreatment and abuse severity within a single study. The present investigation examines self-reported child maltreatment and adult functioning in a geographically diverse sample of 1,396 undergraduate students. Results indicate that experiencing multiple types of maltreatment is positively associated with more severe abuse. Although increased maltreatment types and more severe abuse are each associated with greater trauma symptomatology, abuse severity is the stronger of the two predictors. Finally, number of maltreatment types and severity of maltreatment interact to predict greater levels of trauma symptomatology. These results highlight the importance of considering both co-occurring abuse types and severity in research and clinical work with adult victims.
\end{abstract}

Keywords: child maltreatment, child abuse, long-term effects, multiple abuse, trauma

$\mathrm{A}$ ccording to the U.S. Department of Health and Human Services (2006), 872,000 children were the victims of confirmed child abuse and neglect reported to state child protective services in 2004. Of these cases, $60 \%$ involved neglect, $18 \%$ physical abuse, $10 \%$ sex- ual abuse, and $7 \%$ emotional maltreatment. Not only is abuse prevalent, but child maltreatment in its various forms has been associated with a host of immediate and long-term adverse outcomes including depressive symptoms (Danielson, De Arellano, Kilpatrick, Saunders, \& Resnick, 2005), partner relationship problems (DiLi1lo \& Long, 1999), adult sexual victimization (Messman-Moore \& Brown, 2004), substance abuse (Brown \& Anderson, 1991), aggression (Herrenkohl, Egolf, \& Herrenkohl, 1997), and poor school performance (Kendall-Tackett \& Eckenrode, 1996). Trauma symptomatology is one of the most commonly studied outcomes in the child maltreatment literature. In fact, studies have documented consistent relationships between child sexual and physical abuse and adult posttraumatic stress symptoms (e.g., Boney-McCoy \& Finkelhor, 1996; Schaaf \& McCanne, 1998). Recently, emotional maltreatment has been included as an additional abuse type in examinations of child maltreatment and adult trauma symptoms (Rich, Gidycz, Warkentin, Loh, \& Weiland, 2005). Given the widespread prevalence of child maltreatment and the deleterious outcomes that often result, it is not surprising that this problem has captured the attention of social science researchers during the past 30 years. 


\section{Co-Occurrence of Multiple Forms of Child Maltreatment}

Although researchers have traditionally studied single types of maltreatment, it is becoming increasingly clear than many individuals experience more than one form of child maltreatment, a phenomenon referred to as multitype abuse (Higgins \& McCabe, 2000) or multiple victimization (Rossman, Hughes, \& Hanson, 1998). Rates of co-occurring physical and sexual abuse have varied from $17 \%$ for community samples of children (Hobbs \& Wynne, 1990) to $71 \%$ for samples of inpatient adolescent females (Westen, Ludolph, Misle, Ruffins, \& Block, 1990). Studies of outpatient and college populations have also documented co-occurrence rates of physical and sexual abuse as a child around 30\% (e.g., Mancini, van Ameringen, \& MacMillan, 1995). Claussen and Crittenden (1991) discovered that $91 \%$ of children reported to child protective services for suspected physical abuse also experienced psychological maltreatment. Furthermore, studies that have included emotional abuse in addition to physical and sexual abuse have found co-occurrence rates ranging from $35 \%$ to $45 \%$ (Moeller, Bachmann, \& Moeller, 1993; Mullen, Martin, Anderson, Romans, \& Herbison, 1995). A recent investigation examining the prevalence of sexual abuse, physical abuse, psychological maltreatment, neglect, and witnessing of family violence in a community sample reported that $24.0 \%$ of the sample had experienced one type of abuse, whereas $15.4 \%, 11.4 \%, 9.7 \%$, and $6.9 \%$ of participants reported two, three, four, or five forms of maltreatment, respectively (Higgins \& McCabe, 2000). Another study evaluating relationships among various types of adverse childhood experiences and household dysfunction revealed that individuals reporting a history of child sexual abuse were 2.0 to 3.4 times more likely to report experiencing child physical abuse, emotional abuse, physical neglect, and emotional neglect (Dong, Anda, Dube, Giles, \& Felitti, 2003).

\section{Cumulative Impact of Multiple Types of Child Maltreatment}

Given evidence that abuse types often co-occur, a logical next question is whether coexisting forms of abuse have an additive impact on victims' long-term psychological and social functioning. Indeed, investigations have found greater adjustment difficulties as the number of maltreatment types increases. In the child maltreatment literature, those with documented histories of multiple types of maltreatment have shown greater internalizing and externalizing symptoms, heightened anger, increased depression, more severe posttraumatic stress symptoms, and lowered social competence than children with only one maltreatment type (English, Graham, Litrownik, Everson, \& Bangdiwala, 2005; Lau et al., 2005; Rossman et al., 1998). Within adult clinical and nonclinical samples, concomitant physical and sexual abuse have been associated with heightened psychiatric symptomatology, including posttraumatic stress disorder (Schaaf \& McCanne, 1998) and substance abuse (Brown \& Anderson, 1991). Higgins and McCabe (2000) similarly found that adults reporting three to five forms of child maltreatment experienced greater traumarelated symptoms and lower self-esteem than did those reporting one or two types of abuse. In addition, a retrospective study of neglect and emotional, physical, and sexual abuse in college students found that individuals who had experienced multiple types of abuse reported greater symptoms of depression, suicidality, low selfesteem, substance abuse, sexual difficulties, and delinquent behavior (Arata, Langhinrichsen-Rohling, Bowers, \& O'Farrill-Swails, 2005). Similar relationships between multiple forms of abuse and poorer psychosocial adjustment have also been found among Latina college students (Clemmons, DiLillo, Martinez, DeGue, \& Jeffcott, 2003).

\section{Outcomes Related to Abuse Characteristics}

In addition to the literature examining co-occurring forms of maltreatment, a separate body of research has linked specific characteristics of various maltreatment types to a broad range of short-term (Mennen \& Meadow, 1995; Trickett, Reiffman, Horowitz, \& Putnam, 1997) and long-term negative consequences (Elliott \& Briere, 1992). For example, individuals who experience intrafamilial sexual abuse evince more aggressive delinquency, sexual acting out, and disruptive behavior than do those abused by non-family members (e.g., Trickett et al., 1997). These findings indicate the importance of considering perpetrator identity as a potential indicator of sexual abuse severity. Frequency and duration of abuse have also been linked to greater psychological difficulties in adulthood (English, Upadhyaya, et al., 2005; Steel, Sanna, Hammond, Whipple, \& Cross, 2004). Indicators of long-term outcomes for survivors also include the types of sexual acts experienced and the use of force. For example, children with sexual abuse histories exhibit more depressive symptomatology and destructive behaviors as the frequency of contact sexual abuse experiences increases (Trickett et al., 1997). In addition, the degree of physical force employed during abuse has been associated with both immediate and enduring negative outcomes (e.g., Trickett et al., 1997). 
There is evidence of similar relationships between abuse severity and degree of psychosocial maladjustment for other maltreatment types as well. For example, Schenkel, Spaulding, DiLillo, and Silverstein (2005) found that experiencing more frequent and severe child physical abuse, sexual abuse, and neglect was associated with more hallucinations and delusions in adults diagnosed with schizophrenia spectrum disorders. Likewise, significant associations have been found between child neglect severity and the severity of adult substance use and dependence (Kirisci, Dunn, Mezzich, \& Tarter, 2001). In addition, one study demonstrated a clear doseresponse relationship between psychological abuse severity and adult depression, such that only $37 \%$ of participants with little or no psychological abuse evidenced depressive symptoms, whereas $83 \%$ of participants who reported marked psychological abuse also met criteria for depression (Bifulco, Moran, Baines, Bunn, \& Stanford, 2002). Finally, a recent cluster analysis showed that individuals with long-term adjustment problems were better classified by the degree, rather than the type, of maltreatment they had experienced (Higgins, 2004), providing further support for the role of abuse severity in psychosocial adjustment.

\section{Summary and Rationale for Present Study}

As noted, research has typically examined relationships between single forms of abuse and long-term psychological outcomes. However, recent data also indicate that co-occurring abuse types have a cumulative impact on later functioning. A separate body of literature reveals that abuse severity - as assessed by various characteristics such as frequency and duration of acts, use of force, relationship to offender-also has a bearing on long-term adjustment. Interestingly, there is little research examining whether these two variables (i.e., number of abuse types and abuse severity) interact to predict greater psychological maladjustment in adulthood. Given that both factors have demonstrated strong independent associations with adult adjustment difficulties, it might be expected that experiencing more types of abuse and more severe forms of each type of abuse would result in even more negative adult outcomes. Therefore, the present study will extend past findings by examining not only the relative impact of the number and severity of abuse types but also how these factors might interact to contribute to increased adjustment difficulties for adult survivors. More specifically, it is predicted that

1. There will be modest positive associations among the various forms of maltreatment reported by participants.

2a. Greater numbers of maltreatment types will predict poorer adult adjustment.
$2 b$. The cumulative severity (i.e., summed total of severity across abuse types) of abuse types will predict increased adjustment difficulties.

2c. When considered simultaneously, increasing numbers of abuse types and abuse severity will each be uniquely associated with adult psychological adjustment difficulties.

3 . As the number of abuse types increases among participants, the average abuse severity will also increase.

4. Greater numbers of abuse types and more severe abuse will interact to predict increased psychological adjustment problems.

\section{METHOD}

\section{Participants}

Participants were 1,396 male and female undergraduate students attending the University of Southern California (USC; 36\%), University of Nebraska-Lincoln (UNL; 34\%), and Miami University (MU; 30\%). Nearly three fourths of the sample were female $(72.6 \%)$. The mean age of participants was 20.3 years $(S D=2.30)$, with a range of 17 to 48 years. Participants reported their ethnicity as follows: Caucasian or Euro-American 76.0\%, Asian American 8.5\%, Hispanic or Latin American 5.2\%, African American 3.6\%, Hawaiian Islander $0.3 \%$, Native American $0.1 \%$, and Other or Not Specified $6.2 \%$. Nearly all participants $(96.4 \%)$ reported being unmarried (i.e., never married or currently divorced or separated), whereas $3.6 \%$ were married or cohabitating at the time of the study. Family income during childhood varied, with $19.1 \%$ of the sample reporting an income of less than $\$ 40,000,35.6 \%$ reporting an income between $\$ 40,000$ and $\$ 80,000$, and $44.4 \%$ reporting an income of greater than $\$ 80,000$. In terms of parental education level, $14.8 \%$ of participants indicated that their fathers had completed high school or obtained a GED, $19.7 \%$ had completed some college, $27.6 \%$ had obtained a bachelor's degree, and $38.8 \%$ had pursued graduate-level education or beyond. Participants indicated that $15.8 \%$ of mothers had completed high school or obtained a GED, $16.8 \%$ had completed some college, $28.4 \%$ had obtained a bachelor's degree, and $25.7 \%$ had pursued graduate education.

\section{Measures}

Computer Assisted Maltreatment Inventory (CAMI). The CAMI (DiLillo et al., 2006) is a Web-based, selfreport questionnaire designed to assess a broad range of childhood maltreatment experiences, including sexual abuse, physical abuse, psychological abuse, and neglect. Participants were classified as having either experienced or not experienced each form of maltreatment based on the following definitions. 
Sexual abuse. Participants who reported experiencing, before age 18, actual or attempted sexual touching, sexual kissing, or oral, anal, or vaginal intercourse with a family member or a person who was 5 or more years older were considered victims of sexual abuse. In addition, persons who reported experiencing such activities against their will, regardless of age difference or relationship to the perpetrator, were classified as victims. This study focused only on contact sexual abuse; voluntary sexual play with a similar-age peer and voluntary sexual activities with a dating partner were not included as sexually abusive behavior.

Participants who were classified as sexually abused identified up to three individuals with whom these activities occurred (i.e., perpetrators). For each perpetrator (e.g., father, uncle, foster sister) identified, respondents used a 5-point Likert-type scale ranging from 1 (never happened) to 5 (more than 10 times) to report the frequency of specific acts that occurred (19 items). Respondents also identified their age at onset and at termination of abuse, reported why the abuse ended, and estimated the age of the perpetrator or perpetrators. Finally, participants responded yes or no to 12 questions regarding coercive methods perpetrators may have used to engage in the sexual activity (e.g., use of gifts, threats, physical force).

Physical abuse. Participants who reported that before age 18, a parent or other adult caregiver did something to them on purpose (e.g., kicked, hit with a fist, knocked them down) were considered victims of childhood physical abuse. Respondents who met any of the physical abuse criteria identified up to three perpetrators. Participants used a 5-point Likert-type scale ranging from 1 (never happened) to 5 (more than 10 times) to report the frequency of specific acts that occurred (15 items). Participants responded yes or no to eight questions regarding possible injuries sustained, ranging from relatively minor (e.g., scratches) to major injuries (e.g., broken bones, internal injuries). Finally, respondents reported their age at onset and at termination of abuse and why the abuse ended.

Psychological abuse. The Psychological Abuse subscale was developed based on Hart and Brassard's (1986) model of psychological maltreatment and includes 57 items that reflect five major categories of psychological maltreatment: spurning, terrorizing, isolating, exploiting or corrupting, and denying emotional responsiveness. According to this model, spurning involved verbal and nonverbal acts by caregivers that are rejecting or degrading, including belittling, shaming, ridiculing, criticizing, or publicly humiliating a child. Terrorizing included parental acts that physically threaten or place the child or child's loved ones in physically dangerous situations (e.g., threatening or perpetrating violence against a child or the child's loved ones). Isolating was defined by caregiver behaviors that deny a child the opportunity to interact with peers or adults, including acts such as confining the child's movement within his or her environment and placing unreasonable restrictions on social interactions. Exploiting or corrupting included modeling, allowing, or encouraging antisocial behavior (e.g., substance abuse, prostitution) or developmentally inappropriate behavior (e.g., infantilization, parentification) and restricting cognitive development. Denying emotional responsiveness involved ignoring a child's needs and attempts to interact by acting detached or expressing no affection or love when interacting with him or her. Participants rated each item on this subscale using a 5-point Likert-type scale ranging from 1 (strongly disagree) to 5 (strongly agree). Participants whose total psychological abuse scores (ranging from 0 to 285) fell at or above one standard deviation above the mean $(M=95.0, S D=29.0)$ were considered psychological abuse victims. Although we cannot know whether individuals scoring above this cutoff definitely experienced psychological abuse, this method of identification resulted in an estimated prevalence rate comparable to those found in similar studies (e.g., Moran, Bifulco, Ball, Jacobs, \& Benaim, 2002; Straus \& Savage, 2005). The Psychological Abuse subscale demonstrated good internal consistency, yielding a coefficient alpha of .95 .

Neglect. The Neglect subscale is composed of 38 items that described behaviors commonly identified as neglectful in the child maltreatment literature. Erickson and Egeland (2002) outlined the following subcategories: physical neglect, medical neglect, and educational neglect. Physical neglect referred to failure to protect from harm and provide for a child's basic needs (e.g., food, clothing). Medical neglect was described as failure to provide medical treatment for a child, including immunizations, medication, or other recommended medical interventions. Educational neglect included failure to abide by state guidelines for school attendance. Respondents rated each item on this subscale using a 5-point Likert-type scale ranging from 1 (strongly disagree) to 5 (strongly agree). As with psychological abuse, participants whose total neglect scores (ranging from 0 to 190) fell at or above one standard deviation above the mean $(M=54.8, S D=16.0)$ were considered neglect victims. The Neglect subscale yielded a coefficient alpha of .92 .

Scoring of the CAMI. The CAMI provides both dichotomous (presence or absence) and continuous scores for each type of maltreatment, based on abuse severity. Di- 
chotomous scores were determined using the criteria described for each of the subscales. In addition, the CAMI yields a severity score for individual maltreatment types and a total maltreatment severity score. For the subscales measuring sexual abuse and physical abuse, the severity score consists of the sum of six specific severity indicators (i.e., frequency, duration, nature of acts, relationship to perpetrator, number of perpetrators, and use of force) for each abuse type. For each indicator, a score ranging from 0 (least severe) to 3 (most severe) is computed. A severity score for each abuse type, ranging from 6 to 18 , is calculated by summing the individual severity indicators. So that all abuse subscales are equally weighted, scores of the Psychological Abuse and Neglect subscales are converted to match the same metric (maximum scores of 18) as the Sexual and Physical Abuse subscales. A maltreatment severity score reflecting the combined severity of all maltreatment types is also calculated by summing the individual abuse severity scores to obtain an overall measure of abuse severity experienced by each participant.

Psychometric properties of the CAMI. The CAMI Maltreatment subscales have demonstrated acceptable testretest reliability and criterion-related validity (DiLillo et al., 2006). Test-retest coefficients during a 2- to 4-week interval for the abuse severity scores ranged from $r=.77$ to $r=.95$. Criterion-related validity of the CAMI was evaluated in a sample of college students by examining associations between the severity scores of the individual abuse types and corresponding subscales on the Childhood Trauma Questionnaire (Fink, Bernstein, \& Handelsman, 1994), a well-established measure of maltreatment. Similar sub-scales across the two instruments were significantly and positively correlated ( $r$ values from .47 to .79). Finally, reporting rates of abuse on the CAMI do not appear to vary as a function of mode of administration (computer, printed questionnaire, or interview; DiLillo, DeGue, Kras, Di Loreto-Colgan, \& Nash, 2006).

Trauma Symptom Checklist-40 (TSC-40). The TSC40 (Briere \& Runtz, 1989; Elliott \& Briere, 1992) has been widely used as a general measure of trauma-related symptoms among abuse survivors. It consists of 40 items that assess adult symptoms associated with traumatic childhood or adulthood experiences. Respondents use a 4-point scale ranging from 0 (never) to 3 (often) to rate the frequency with which they had experienced each symptom during the past 2 months. The TSC Total score demonstrates strong internal reliability ( $\alpha$-values ranging from .89 to .91; Briere \& Runtz, 1989; Elliott \& Briere, 1992) and was selected as the primary outcome variable for the study.

\section{Procedure}

Data were collected as a part of a larger project exploring adult adjustment associated with a history of childhood maltreatment. Institutional review board approval was obtained at all three institutions where data collection occurred. Participants were recruited from a variety of undergraduate psychology courses. At two institutions (UNL and MU), participants signed up for the study through an online Web site that tracks participation in departmental experiments. Students at the other institution were recruited in person by researchers who entered classrooms and advertised the study. All participants logged onto the same Web site to complete the CAMI and the TSC-40 and other instruments not included in this study. Participants received class credit for their participation. Data from all universities were stored on a secure server at UNL.

\section{RESULTS-MALTREATMENT CHARACTERISTICS OF THE SAMPLE}

In the current sample, $8.2 \%$ of participants $(n=114)$ reported sexual abuse before age 18 , with more than one third $(n=42)$ of these respondents endorsing intercourse as their most severe type of abuse. Among sexual abuse victims, $75.0 \%(n=86)$ indicated that the abuse occurred during a time frame of 1 year or less, and $19.0 \%(n=22)$ reported either two or three perpetrators. A total of $58.0 \%$ $(n=66)$ of victims indicated they had been abused by acquaintances or non-family members, with fewer than $10.0 \%(n=10)$ reporting sexual abuse by a parental figure. More than half $(n=58)$ of the sexual abuse victims reported that their perpetrators used verbal tactics (e.g., manipulation), whereas more than one third $(n=39)$ indicated that threats of physical violence or actual physical force were part of their abuse.

Physical abuse was the most commonly reported form of abuse, with nearly $20 \%$ of the sample $(n=266)$ reporting this form of maltreatment. Approximately 97\% of participants $(n=259)$ indicated that parents perpetrated physical abuse. Within this subsample, $33 \%$ of participants $(n=88)$ reported that their most severe form of physical abuse included being choked, beaten repeatedly, or burned. Although $30 \%$ of physical abuse victims $(n=80)$ reported no injuries, $10 \%(n=25)$ suffered injuries as severe as broken bones, burns, and internal injuries. Finally, more than $80 \%$ of participants within this subsample $(n=93)$ reported physical abuse that occurred on more than 10 occasions, whereas $76 \%(n=$ 202) reported that their abuse lasted for a period of more than 2 years. 
Table 1: Intercorrelations for the Presence of Four Different Maltreatment Types

\begin{tabular}{lllll}
\hline Maltreatment Type & 1 & 2 & 3 & 4 \\
\hline 1. Sexual abuse & - & & & \\
2. Physical abuse & .16 & - & & \\
3. Psychological abuse & .14 & .35 & - & \\
4. Neglect & .11 & .21 & .51 & - \\
\hline
\end{tabular}

Note: All coefficients are significant at $p<.01$.

Of the total sample, $14 \%(n=195)$ met the criteria for psychological maltreatment, with a mean psychological abuse scale score of $2.6(S D=0.43)$ on items ranging from 1 (strongly disagree) to 5 (strongly agree). Of these respondents, $60 \%(n=117)$ agreed or strongly agreed that their parents frightened them, whereas 55\% $(n=$ 107 ) agreed or strongly agreed that they were cursed at or threatened with physical violence. Approximately $35 \%$ $(n=69)$ of psychologically abused participants agreed or strongly agreed that their parents made them cry for no good reason and made them "feel like a bad person." With respect to extreme items, $15 \%(n=29)$ reported that their parents threatened to leave and never come back, whereas $10 \%$ of psychological abuse victims $(n=19)$ indicated that their parents had threatened to kill or harm one of their pets.

As with psychological abuse, $14 \%$ of the sample ( $n$ $=195$ ) met criteria for neglect. These participants had a mean neglect scale score of $2.3(S D=0.42)$ on items ranging from 1 (strongly disagree) to 5 (strongly agree) and endorsed a broad range of negative parenting behaviors. For example, $35 \%$ of these participants $(n=68)$ agreed or strongly agreed that they had access to dangerous objects (e.g., guns, knives, household chemicals) during childhood. A total of $32 \%$ of neglected participants $(n$ $=62$ ) agreed or strongly agreed that they were left unsupervised, with people they did not know, or at public places for long periods. Also, $17 \%(n=33)$ reported that food often spoiled at their homes, whereas $20 \%(n=39)$ indicated that they missed meals as a child. Finally, more than $10 \%$ of neglect victims $(n=20)$ reported living in either broken-down or dirty homes.

To determine the extent of co-occurrence among the various forms of maltreatment, a summary score was computed, ranging from 0 to 4 , to reflect the total number of abuse types experienced by each participant. Within the entire sample $(N=1,396), 20 \%$ of participants reported a single type of maltreatment, and $14 \%$ of the sample ( $n$ $=198)$ reported either two $(n=119)$, three $(n=62)$, or all four $(n=17)$ forms of maltreatment. For individuals who reported abuse of any kind, the most commonly reported co-occurring maltreatment types were psychological abuse and neglect (9.7\%), physical and psychological abuse (7.3\%), and sexual and physical abuse (3.8\%).

To further explore the relationships among individual maltreatment types, each abuse type was recoded into a dichotomous variable reflecting whether or not that abuse type occurred, and the degree of association between each form of maltreatment was examined using Spearman's rho correlations (see Table 1). Although all coefficients were significant $(p<.01)$, results indicated low-tomoderate positive correlations between individual types, with $r$ values ranging from .11 between sexual abuse and neglect to .51 between psychological abuse and neglect (mean $r=.25$ ). As such, on average there were moderate associations between the various abuse subtypes.

To examine the relationship between numbers of abuse types and psychological adjustment, a multiple regression model was employed. In this model, the summary score reflecting the numbers of abuse types $(0-4)$ for all participants served as the predictor variable, and the TSC-40 total score was used as the criterion. The number of abuse types reported by participants was a significant predictor of trauma symptomatology $\left(R^{2}=.13, B=6.78\right.$, $S E B=0.49, \beta=.37, p<.001)$, indicating that $13 \%$ of the variance in trauma symptomatology was accounted for by the number of maltreatment types experienced.

To examine the cumulative impact of all reported maltreatment experiences, the relationship between maltreatment severity (summed across individual abuse types) and psychological adjustment was examined in a separate regression model, utilizing the maltreatment severity as the predictor variable and the TSC-40 total score as the criterion. As expected, overall maltreatment severity experienced by participants was a significant predictor of trauma symptomatology $\left(R^{2}=.08, B=0.56, S E B\right.$ $=0.09, \beta=.29, p<.001)$, accounting for $8 \%$ of the variance in trauma scores.

Finally, a simultaneous regression model was utilized to examine the unique relationships between numbers of abuse types and overall abuse severity to adjustment. Because only victims had severity scores, only these individuals were included in this model. Summary scores reflecting the numbers of abuse types (1-4) and the total maltreatment severity scores of participants who reported at least one kind of maltreatment were simultaneously entered as predictor variables, and the TSC-40 total score was used as the criterion variable. Results revealed that the number of abuse types and total maltreatment severity scores combined to predict the level of trauma symptomatology among participants, $R^{2}=.08$ $(p<.001)$. 
Table 2: Correlations Between Individual Maltreatment Severity Scores and Number of Maltreatment Types

\begin{tabular}{lcrcc}
\hline Type of Maltreatment & Severity Score & $\mathrm{n}$ & MSD & $\mathrm{r}$ \\
\hline Sexual abuse & 114 & 10.16 & 2.30 & $.29^{* *}$ \\
Physical abuse & 266 & 12.64 & 2.22 & $.26^{* *}$ \\
Psychological abuse & 197 & 8.90 & 1.60 & $.32^{* *}$ \\
Neglect & 197 & 7.61 & 1.53 & $.21^{* *}$ \\
\hline
\end{tabular}

Note: Scales for all maltreatment severity scores have a possible range of 0 to 18 . $* * p$

Table 3: Hierarchical Regression Analysis Summary for Centered (Number of Maltreatment Types and Maltreatment Severity Average) and Interaction Variables Predicting Trauma Symptom Checklist Scores

\begin{tabular}{lccccc}
\hline Variable & B & SEB & $\beta$ & $R^{2}$ & $\Delta R^{2}$ \\
\hline $\begin{array}{l}\text { Step 1 } \\
\quad \text { Number of maltreatment } \\
\quad \text { types }\end{array}$ & 5.99 & 1.02 & $.27^{* * *}$ & $.07 * * *$ \\
$\quad \begin{array}{l}\text { Maltreatment severity } \\
\quad \text { average }\end{array}$ & 0.41 & 0.37 & .05 & & \\
$\begin{array}{l}\text { Step } \\
\quad \text { Interaction term }\end{array}$ & 1.25 & 0.57 & $.11^{*}$ & & \\
\hline
\end{tabular}

${ }^{*} p<.05 .{ }^{* * *} p<.001$.

Together, these variables accounted for $8 \%$ of the variance among participants' trauma scores. However, only overall maltreatment severity made a significant contribution to the prediction of trauma symptomatology $(B=$ $0.51, \beta=.26, p<.05)$.

Bivariate correlations were run to examine associations among numbers of abuse types and all individual maltreatment severity scores. Table 2 presents the means and standard deviations of the maltreatment severity scores and the correlations between these scores and the number of abuse types experienced by participants. The number of maltreatment types experienced by participants was significantly and positively correlated with all of the individual maltreatment severity scores $(p<.01)$. These results indicate modest correlations between the number of maltreatment types experienced by participants and individual severity scores, with $r$ values ranging from .21 for neglect to .32 for psychological abuse.

To determine whether there was an interaction between numbers of abuse types and abuse severity as they relate to psychological adjustment among participants, a hierarchical regression model was employed. In these analyses, average severity was used to control for the natural association that would be expected between greater numbers of abuse types and overall severity. An average maltreatment severity score was created by dividing all participants' total maltreatment severity scores by the number of abuse types they experienced. In this model, number of types and the average maltreatment severity score were centered and then separately entered into a regression model as predictors, followed by an interaction term representing their product with the TSC40 total score as the criterion variable. To assess multicollinearity, we examined both the correlation between the predictor variables, which was found to be $r=.045$, and the predictor variable variance inflation factor (VIF statistic), which was 1.00 . Neither suggested the presence of multicollinearity.

Table 3 depicts results from this analysis. The first step indicated that only number of abuse types was a significant predictor of trauma symptoms among participants who reported one or more maltreatment type, $R^{2}=.07(p<.001)$. This analysis revealed that the number of abuse types accounted for $7 \%$ of the variance in the trauma symptomatology among participants, $\Delta F(2$, $436)=17.93, p<.001$. Step 2 indicated an interaction between number of abuse types and the average maltreatment severity. This suggests that beyond the variance explained by number of abuse types, an additional $1 \%$ of the variance in trauma symptoms reported by participants was accounted for by the interaction between number of abuse types and maltreatment severity, $\Delta F(1,435)$ $=4.71, p<.05$.

To further examine the relationship between these two predictors and participants' trauma symptomatology, the interaction was plotted (see Figure 1). Using conventional methods described by Aiken and West (1991), the interaction was plotted to demonstrate the relationships between the number of abuse types experienced and trauma symptomatology for the average abuse severity, abuse severity one standard deviation below the mean, and abuse severity one standard deviation above the mean. The plot reveals an interaction pattern in which average maltreatment severity appears to enhance the contribution of number of maltreatment types to participants' TSC scores, where number of maltreatment types was at least one standard deviation above the mean. However, as the number of maltreatment types fell below this point, average maltreatment severity appeared to buffer the contribution of number of maltreatment types to participants' trauma symptomatology.

\section{DISCUSSION}

The present study sought to integrate previous research by examining both the co-occurrence and sever- 

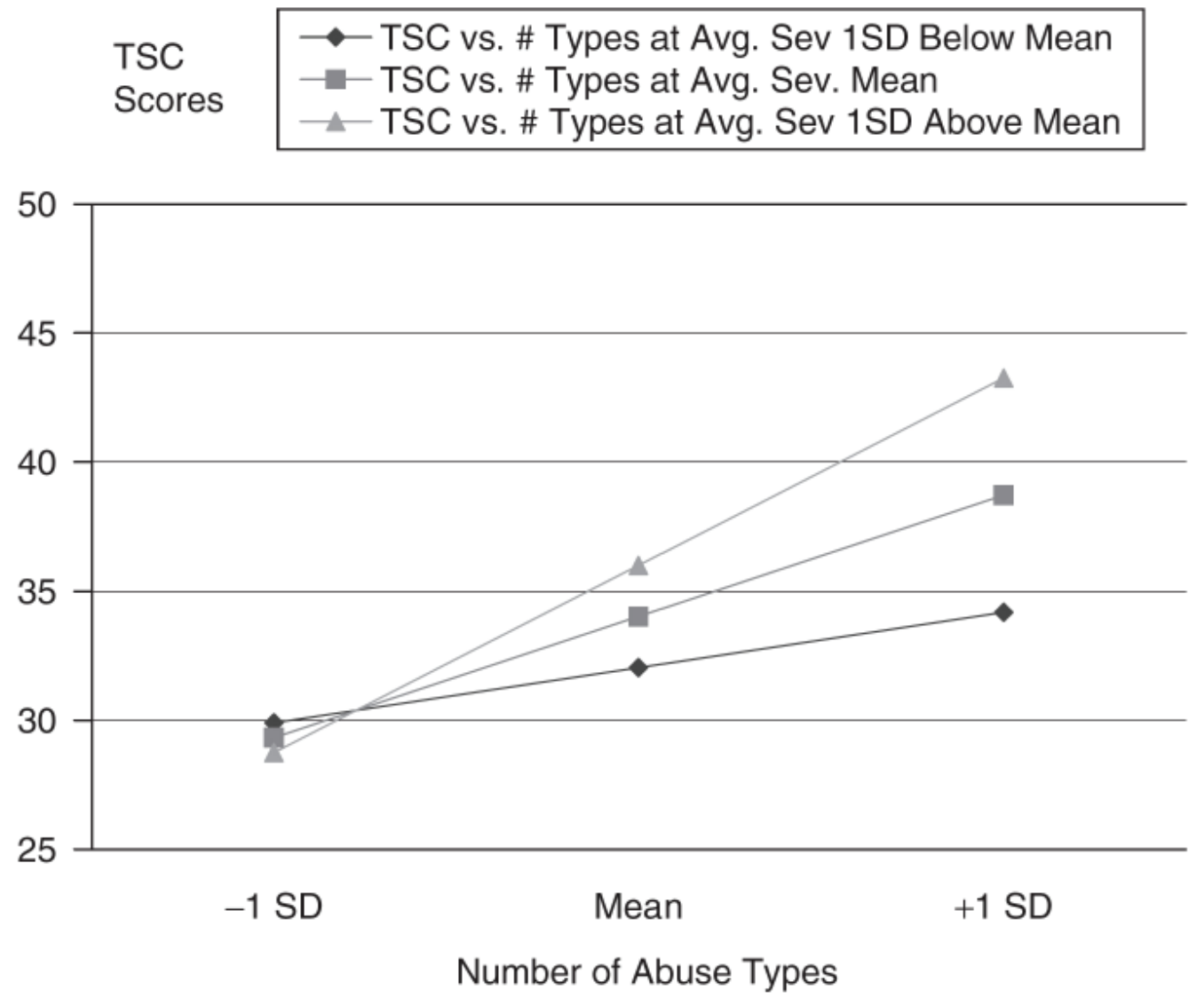

Figure 1: Interaction Plot of Number of Maltreatment Types Versus Average Maltreatment Severity Scores as Related to Trauma Symptom Checklist (TSC) Scores

ity of abuse types in predicting long-term psychological functioning. Although $14 \%$ of participants reported multiple forms of maltreatment, this figure was substantially less than some others, such as the $43 \%$ co-occurrence rate reported by Higgins and McCabe (2000). However, in that study, the co-occurrence rate may have been increased because of the inclusion of witnessing domestic violence as an additional abuse type. In addition, victims and nonvictims in that study were classified via mean cutoffs on continuous maltreatment scales, a rather liberal procedure that may have inflated overall abuse rates. Nevertheless, other studies have found rates of co-occurrence ranging from $17 \%$ to $30 \%$ for community and college samples (e.g., Clemmons et al., 2003; Hobbs \& Wynne, 1990), suggesting that the current sample reported somewhat lower levels of co-occurring maltreatment than might be expected.

Consistent with prior research (e.g., Higgins \& McCabe, 2000; Trickett et al., 1997), number of abuse types and total maltreatment severity were independently asso- ciated with poorer psychological functioning. However, when examined relative to each other, only total severity emerged as a significant predictor of trauma symptoms. This finding corroborates recent research regarding the importance of considering indicators of abuse severity in exploring victim outcomes (e.g., Higgins, 2004). Specifically, it is crucial for researchers to go beyond simple classifications of individuals as either abused or nonabused and to consider the various characteristics (frequency, duration, nature of acts, use of force) that, cumulatively, are indicators of severity of these complex experiences.

When individual abuse types were examined, positive associations were found between severity scores and number of abuse types experienced. However, there was no such association between average maltreatment severity and number of abuse types. This suggests that relationships between single types of abuse and severity become diffuse in the context of additional forms of abuse. Nonetheless, as hypothesized, average maltreatment se- 
verity interacted with number of abuse types to predict adult trauma symptoms. More specifically, the number of abuse types predicted trauma symptoms only in cases in which maltreatment was very severe. These results are consistent with prior studies that have separately underscored the relevance of severity of abuse (Mennen $\&$ Meadow, 1995) and number of abuse types (Arata et al., 2005; Clemmons et al., 2003; Higgins \& McCabe, 2000) to long-term psychological functioning. However, the present findings extend past work by suggesting that number of abuse types may be relevant to adult trauma symptoms only in the context of higher than average severity.

The present investigation has limitations that should be considered. For example, although the sample was geographically diverse, it was relatively homogeneous in terms of age, education, and socioeconomic status, indicating that results may not generalize to all abuse survivors. Furthermore, although ethnically diverse for a college sample, African American and Latino participants were underrepresented relative to national statistics. Despite using a well-validated maltreatment history measure, it is possible that participants' recall of early maltreatment experiences may have been distorted by the passage of time. Relatedly, although the one standard deviation threshold used to identify victims of psychological maltreatment and neglect produced rates of abuse similar to other studies (e.g., Moran et al., 2002; Straus \& Savage, 2005), the nature of these abuse types makes the establishment a firm cutoff somewhat subjective. In the future, efforts could be made to corroborate retrospective reports with other sources of information (sibling reports, official records) or to follow participants longitudinally from the time of abuse into adulthood. Longitudinal studies also are needed to better illuminate causal relationships between co-occurring maltreatment and outcomes for victims - something not afforded by the current cross-sectional design. In addition, although the interaction term describing the impact of number of abuse types and abuse severity on adult trauma symptoms was statistically significant, it only accounted for an additional $1 \%$ of the variance over and above individual factors. Finally, the present study focused on outcomes related to trauma symptomatology, which is but one of the many possible consequences of abuse.

The current investigation has implications for clinical work with survivors of child maltreatment. Here, a substantial minority (14\%) of college students experienced multiple forms of abuse. This trend appears to increase within treatment-seeking samples (e.g., Westen et al., 1990). Although individual forms of child maltreatment, particularly sexual abuse, have long been recognized as precursors to a variety of adult adjustment problems, the present study adds to a growing literature suggesting the need for practitioners to consider the long-term cumulative impact of multiple forms of child maltreatment. That is, clinicians providing services for maltreatment survivors should thoroughly assess all forms of abuse experienced by these individuals so that interventions can be accordingly implemented. Similarly, the heightened maltreatment severity reported by participants with multiple abuse types further underscores the need for a thorough assessment of survivors' maltreatment experiences, which might allow practitioners to more effectively target related psychosocial difficulties. Interventions for abuse victims should also account for the possibility that multiply abused individuals who report more extreme abuse may evidence more severe, long-term trauma symptoms. Finally, although the timing of abuse was not assessed here, the frequent co-occurrence of abuse types suggests that intervening early with child victims of maltreatment may reduce risk of additional trauma exposure.

\section{REFERENCES}

Aiken, L. S. \& West, S. G. (1991). Multiple regression: Testing and interpreting interactions. Thousand Oaks, CA: Sage Publications.

Arata, C., Langhinrichsen-Rohling, J., Bowers, D., \& O'FarrillSwails, L. (2005). Single versus multitype maltreatment: An examination of the long-term effects of child abuse. Journal of Aggression, Maltreatment \& Trauma, 11, 29-52.

Bifulco, A., Moran, P. M., Baines, R., Bunn, A., \& Stanford, K. (2002). Exploring psychological abuse in childhood: II. Association with other abuse and adult clinical depression. Bulletin of the Menninger Clinic, 66, 241-266.

Boney-McCoy, S., \& Finkelhor, D. (1996). Is youth victimization related to trauma symptoms and depression after controlling for prior symptoms and family relationships? A longitudinal, prospective study. Journal of Consulting and Clinical Psychology, $64,1406-1416$.

Briere, J., \& Runtz, M. (1989). The Trauma Symptom Checklist (TSC-33): Early data on a new scale. Journal of Interpersonal Violence, 4, 151-163.

Brown, G. R., \& Anderson, B. (1991). Psychiatric morbidity in adult inpatients with childhood histories of sexual and physical abuse. American Journal of Psychiatry, 148, 55-61.

Claussen, A. H., \& Crittenden, P. M. (1991). Physical and psychological maltreatment: Relations among types of maltreatment. Child Abuse \& Neglect, 15, 5-18.

Clemmons, J. C., DiLillo, D., Martinez, I. G., DeGue, S., \& Jeffcott, M. (2003). Co-occurring forms of child maltreatment and adult adjustment reported by Latina college students. Child Abuse \& Neglect, 27, 751-767.

Danielson, C. K., De Arellano, M. A., Kilpatrick, D. G., Saunders, B. E., \& Resnick, H. S. (2005). Child maltreatment in depressed adolescents: Differences in symptomatology based on history of abuse. Child Maltreatment, 10, 37-48.

DiLillo, D., DeGue, S., Kras, A., Di Loreto-Colgan, A., \& Nash, C. L. (2006). Participant responses to retrospective surveys of child maltreatment: Does mode of assessment matter? Violence and Victims, 21, 410-424.

DiLillo, D., Hayes, S., Fortier, M. A., Perry, A. R., Evans, S., Messman-Moore, T. L., et al. (2006). Comprehensive assessment of child maltreatment history: Development and initial psychometric evaluation of the Computer Assisted Maltreatment Inventory 
(CAMI). Manuscript submitted for publication.

DiLillo, D., \& Long, P. J. (1999). Perceptions of couple functioning among female survivors of child sexual abuse. Journal of Child Sexual Abuse, 7, 59-75.

Dong, M., Anda, R. F., Dube, S. R., Giles, W. H., \& Felitti, V. J. (2003). The relationship of exposure to childhood sexual abuse to other forms of abuse, neglect, and household dysfunction during childhood. Child Abuse \& Neglect, 27, 625-639.

Elliott, D. M., \& Briere, J. (1992). Sexual abuse trauma among professional women: Validating the Trauma Symptom Checklist-40. Child Abuse \& Neglect, 16, 391-398.

English, D. J., Graham, J. C., Litrownik, A. J., Everson, M., \& Bangdiwala, S. I. (2005). Defining maltreatment chronicity: Are there differences in child outcomes? Child Abuse \& Neglect, 29, $575-595$.

English, D. J., Upadhyaya, M. P., Litrownik, A. J., Marshall, J. M., Runyan, D. K., Graham, J. C., et al. (2005). Maltreatment's wake: The relationship of maltreatment dimensions to child outcomes. Child Abuse \& Neglect, 29, 597-619.

Erickson, M. F., \& Egeland, B. (2002). Child neglect. In J. E. B. Myers, L. Berliner, J. Briere, C. T. Hendrix, C. Jenny, \& T. A. Reid (Eds.), The APSAC handbook on child maltreatment (pp. 3-20). Thousand Oaks, CA: Sage.

Fink, L. A., Bernstein, D., \& Handelsman, L. (1994). Initial reliability and validity of a new retrospective measure of child abuse and neglect. American Journal of Psychiatry, 15, 1132-1136.

Hart, S. N., \& Brassard, M. R. (1986). Developing and validating operationally defined measures of emotional maltreatment: A multimodal study of the relationship between caretaker behaviors and children characteristics across three developmental levels (DHHS90CA1216). Washington, DC: U.S. Department of Health and Human Services and National Center on Child Abuse and Neglect.

Herrenkohl, R. C., Egolf, B. P., \& Herrenkohl, E. C. (1997). Preschool age antecedents of adolescents assaultive behavior: Results from a longitudinal study. American Journal of Orthopsychiatry, 67, 422-432.

Higgins, D. J. (2004). The importance of degree versus type of maltreatment: A cluster analysis of child abuse types. Journal of Psychology, 138, 303-324.

Higgins, D. J., \& McCabe, M. P. (2000). Multi-type maltreatment and the long-term adjustment of adults. Child Abuse Review, 9, 6-18.

Hobbs, C. J., \& Wynne, J. M. (1990). Sexually abused battered child. Archives of Diseases in Childhood, 65, 423-427.

Kendall-Tackett, K. A., \& Eckenrode, J. (1996). The effects of neglect on academic achievement and disciplinary problems: A developmental perspective. Child Abuse \& Neglect, 20, 161-169.

Kirisci, L., Dunn, M. G., Mezzich, A. C., \& Tarter, R. E. (2001). Impact of parental substance use disorder and child neglect severity on substance use involvement in male offspring. Prevention Science, 2, 241-255.

Lau, A. S., Leeb, R. T., English, D., Graham, J. C., Briggs, E. C., Brody, K. E., et al. (2005). What's in a name? A comparison of methods for classifying predominant type of maltreatment. Child Abuse \& Neglect, 29, 533-551.

Mancini, C., van Ameringen, M., \& MacMillan, H. (1995). Relationship of childhood sexual and physical abuse to anxiety disorders. Journal of Nervous and Mental Disease, 183, 309-314.

Mennen, F. E., \& Meadow, E. (1995). The relationship of abuse characteristics to symptoms in sexually abused girls. Journal of Interpersonal Violence, 10, 259-274.

Messman-Moore, T. L., \& Brown, A. L. (2004). Child maltreatment and perceived family environment as risk factors for adult rape: Is child sexual abuse the most salient experience? Child Abuse \& Neglect, 28, 1019-1034.

Moeller, T. P., Bachmann, G. A., \& Moeller, J. R. (1993). The combined effects of physical, sexual and emotional abuse during childhood: Long-term health consequences for women. Child
Abuse \& Neglect, 17, 623-640.

Moran, P. M., Bifulco, A., Ball, C., Jacobs, C., \& Benaim, K. (2002). Exploring psychological abuse in childhood: I. Developing a new interview scale. Bulletin of the Menninger Clinic, 66, 241-258.

Mullen, P. E., Martin, J. L., Anderson, J. C., Romans, S. E., \& Herbison, G. P. (1995). The long-term impact of the physical, emotional, and sexual abuse of children: A community study. Child Abuse \& Neglect, 20, 7-21.

Rich, C. L., Gidycz, C. A., Warkentin, J. B., Loh, C., \& Weiland, P. (2005). Child and adolescent abuse and subsequent victimization: A prospective study. Child Abuse \& Neglect, 29, 1373-1394.

Rossman, B. B. R., Hughes, H. M., \& Hanson, K. L. (1998). The victimization of school-age children. Journal of Aggression, Maltreatment, and Trauma, 2, 87-106.

Schaaf, K. K., \& McCanne, T. R. (1998). Relationship of childhood sexual, physical, and combined sexual and physical abuse to adult victimization and posttraumatic stress disorder. Child Abuse \& Neglect, 22, 1119-1133.

Schenkel, L. S., Spaulding, W. D., DiLillo, D., \& Silverstein, S. M. (2005). Histories of childhood maltreatment in schizophrenia: Relationships with premorbid functioning, symptomatology, and cognitive deficits. Schizophrenia Research, 76, 273-286.

Steel, J., Sanna, L., Hammond, J., Whipple, J., \& Cross, H. (2004). Psychological sequelae of child sexual abuse: Abuse-related characteristics, coping strategies, and attributional style. Child Abuse \& Neglect, 28, 785-801.

Straus, M. A., \& Savage, S. A. (2005). Neglectful behavior by parents in the life history of university in 17 countries and its relation to violence against dating partners. Child Maltreatment, 10, 124-135.

Trickett, P. K., Reiffman, A., Horowitz, L. A., \& Putnam, F. W. (1997). Characteristics of sexual abuse trauma and the prediction of developmental outcomes. In D. Cicchetti \& S. Toth (Eds.),

Rochester symposium on developmental psychopathology: Developmental perspectives on trauma: Theory, research, and intervention (pp. 289314). Rochester, NY: University of Rochester Press.

U.S. Department of Health and Human Services. (2006). C C h ild maltreatment 2004: Reports from the states to the National Child Abuse and Neglect Data System. Washington, DC: Government Printing Office.

Westen, D., Ludolph, P., Misle, B., Ruffins, S., \& Block, J. (1990). Physical and sexual abuse in adolescent girls with borderline personality disorder. American Journal of Orthopsychiatry, 60, $55-66$.

John C. Clemmons, Ph.D., is Assistant Professor of Pediatrics at the University of Arkansas for Medical Sciences. His clinical appointment is divided between the Family Treatment Program and the Adolescent Sexual Adjustment Project within the Center for Children at Risk located at Arkansas Children's Hospital.

Kate Walsh is a doctoral student in the Clinical Psychology Training Program at the University of Nebraska at Lincoln. Her research interests include child maltreatment, interpersonal violence, and posttraumatic stress disorder.

David DiLillo, Ph.D., is an Associate Professor and Director of Clinical Training in the Department of Psychology at the University of Nebraska at Lincoln. His research interests lie in the area of family violence, particularly the long-term correlates of child maltreatment.

Terri L. Messman-Moore, Ph.D., is currently an associate professor of clinical psychology at Miami University. Her research interests include factors that influence sexual revictimization and the impact of childhood maltreatment and sexual violence on interpersonal functioning and health-risk behavior among young women. 